\title{
Marriage Satisfaction and Wellness in India and the United States: A Preliminary Comparison of Arranged Marriages and Marriages of Choice
}

\author{
Jane E. Myers, Jayamala Madathil, and Lynne R. Tingle
}

Forty-five individuals (22 couples and 1 widowed person) living in arranged marriages in India completed questionnaires measuring marital satisfaction and wellness. The data were compared with existing data on individuals in the United States living in marriages of choice. Differences were found in importance of marital characteristics, but no differences in satisfaction were found. Differences were also found in 9 of 19 wellness scales between the 2 groups. Implications for further research are considered.

Marriage is an important institution in almost all societies in the world. In the United States, for example, over $90 \%$ of persons choose to marry at some point in their lives (Brubaker \& Kimberly, 1993). The results of numerous studies suggest that people tend to be both healthier and happier when they are married (e.g., Gottman, 1994; Orbuch \& Custer, 1995; White, 1994). As a consequence, the most frequently studied aspect in research on marriage and family relationships is that of satisfaction, or what helps people maintain happiness in their marriages (Heyman, Sayers, \& Bellack, 1994; Larson et al., 1995; Spanier, 1976). A second concept that has received much attention in the literature relates to the processes by which individuals develop intimate relationships and, in particular, how love develops over time (Murstein, 1987; Sher, 1996; Sternberg, 1986). However, few studies have examined how factors such as love, intimacy, happiness, and satisfaction differ in marriages across cultures (Kail \& Cavanaugh, 2000). In an increasingly diverse and global society, knowledge of cross-cultural differences in relationships and relationship satisfaction is important information for counselors.

Buss et al. (1990), working with a large team of researchers, administered surveys to 9,494 adults from 33 countries to determine the effects of culture and gender on heterosexual mate preferences. They found that men and women around the world agree that love and mutual attraction are the most important factors in mate selection. Additional factors that received near-universal support were dependability, emotional stability, kindness, and understanding.

Buss et al. (1990) noted that in countries where more traditional values are the norm, such as China, India, and
Iran, men place a high value on women's chastity, their desire for home and children, and their abilities as cook and homemaker. In these same societies, women value men with ambition, with good financial prospects, and men who hold favorable social status. Earlier studies by Udry (1974) revealed that the criteria used in the selection of spouses vary according to the type of mate-selection system in a particular country. Where mate selection is autonomous, which is the prevalent mode in Western societies, interpersonal attraction or "romantic love" is likely to be considered the primary or legitimate basis for marriage. In countries with collectivist orientations, what Buss et al. referred to as "traditional societies," mate selection is often accomplished by the family rather than the individual (Chang \& Myers, 1997; Dion \& Dion, 1993). Important criteria for selecting the individuals to be joined as a couple in these societies include subsistence skills, family alliances, economic arrangements between families, and health (Udry, 1974).

Although demographic factors related to mate selection in traditional and modern cultures have been studied (e.g., Buss et al., 1990), few studies of marital satisfaction in arranged marriages or studies comparing satisfaction in arranged marriages with satisfaction in marriages of choice have been conducted. In one of the few such studies, Shachar (1991) surveyed 206 young married couples from Israel to determine differences in marital satisfaction in arranged marriages and in marriages in which spouses were selected autonomously. He found that the duration of courtship, premarital cohabitation, and patterns of spouse selection were only minimally related to marriage satisfaction.

\footnotetext{
Jane E. Myers and Jayamala Madathil, Department of Counseling and Educational Development; Lynne R. Tingle, Educational Research and Measurement, all at The University of North Carolina at Greensboro. Jayamala Madathil is now at the Department of Counseling and Human Services, University of Colorado at Colorado Springs; Lynne R. Tingle is now a private consultant in Charlotte, North Carolina. Correspondence concerning this article should be addressed to Jane E. Myers, Department of Counseling and Educational Development, The University of North Carolina at Greensboro, PO Box 26171, Greensboro, NC 27402-6171 (e-mail: jemyers@uncg.edu).
} 
Yelsma and Athappilly (1988) studied marriage satisfaction and communication practices of 28 Indian couples in arranged marriages, 25 Indian couples in "love" marriages (marriages of choice), and 31 American couples in companionate marriages. They found that persons in arranged marriages had higher marital satisfaction scores, as measured by the Dyadic Adjustment Scale (Spanier, 1976), than either the love-married persons in India or the companionatemarried persons in the United States. Furthermore, their results indicated that husbands and wives in arranged marriages were more satisfied with their marital relationships than were the husbands and wives in the U.S. sample. In contrast to these findings, in a partial replication of this study with a sample of 586 married women in the People's Republic of China, Xiaohe and Whyte (1990) found that women in freechoice marriages were consistently more satisfied with their marital relationship than were women in arranged marriages. They also found that the women who had been married for 20 to 24 years reported having a higher quality of marriage than did women who had been married for fewer years.

The research on satisfaction in arranged marriages remains equivocal. Furthermore, no studies have examined marital satisfaction in relation to the sense of well-being or wellness of couples because these are related to the mate-selection process. The present study was undertaken to examine the relationships among marital satisfaction and holistic wellness in couples living in the United States in marriages of choice and couples in India in arranged marriages. Specifically, the following research questions were explored: Are there differences in the importance of marriage characteristics, satisfaction with marriage characteristics, or overall marital satisfaction between persons living in India in arranged marriages and persons living in the United States in marriages of choice? Are there differences in wellness characteristics between persons living in India in arranged marriages and persons living in the United States in marriages of choice?

\section{Method}

The procedures for this study involved the administration of wellness and marital satisfaction measures to individuals living in India in arranged marriages and comparisons of their scores with those of married individuals living in the United States in marriages of choice. The scores of the U.S. participants were accessed from preexisting databases. The participants from India were a convenience sample of volunteers from the state of Kerala in southern India. These individuals were members of social and religious groups of which the second author was also a member.

\section{Instruments}

Two instruments were used in this study: the Characteristics of Marriage Inventory (CHARISMA; Rosen-Grandon, Hattie, \& Myers, 2002; Rosen-Grandon, Myers, \& Hattie, 2004) and the Wellness Evaluation of Lifestyle (WEL; Myers, Sweeney, Hattie, \& Witmer, 1998). A demographic form provided information on gender, age, educational level, marital status, length of marriage, influence on the marriage decision-making process, number of children, and living arrangements.

CHARISMA (Rosen-Grandon et al., 2002; Rosen-Grandon et al., 2004) was developed as a brief measure of characteristics related to marital satisfaction. Eighteen characteristics of marriage derived from an extensive literature search are provided in a list, and respondents are asked to indicate first the importance to them of each characteristic and then their satisfaction with each characteristic. Responses are provided using a 6-point Likert-type scale ranging from extremely unimportant (1) to extremely important (6). A final item at the end of the list assesses overall marital satisfaction. Scores for the two scales, importance and satisfaction, are simple sums of the responses to each item in the scale. Only 10 of the 18 characteristics are scored; the remaining characteristics are included for research purposes and are not scored.

Alpha coefficients for a sample of 201 U.S. adults are reported as .83 and .94 for the importance and satisfaction scales, respectively (Rosen-Grandon et al., 2002; RosenGrandon et al., 2004). Concurrent validity studies were conducted using the Dyadic Adjustment Scale (Spanier, 1976) and ENRICH (Olson, Fournier, \& Druckman, 1987). The CHARISMA importance scale correlated $.16(p<.05)$ with the DAS Marital Satisfaction scale, while the CHARISMA satisfaction scale correlated highly with all of the DAS scales: .30 with Affectional Expression, .56 with Consensus, and .50 with Marital Satisfaction. Correlations between the importance scale and three of the ENRICH scales were significant (Communication, .17; Sexual Relations, .28; and Marital Roles, -.14). Four of the five ENRICH scales correlated significantly with the satisfaction scale, while the correlation of Marital Roles with the satisfaction scale was not significant (-.12).

Factor analyses revealed three factors underlying each of the two CHARISMA scales: Love, Loyalty, and Shared Values (Rosen-Grandon et al., 2002; Rosen-Grandon et al., 2004). The marital characteristics in each of the two factors are the same. For example, the Love factor for both the importance and satisfaction scales includes the characteristics of respect, forgiveness, romance, and sensitivity/support. Factor loadings for the importance and satisfaction scales, respectively, on the four characteristics are reported as .60 and .77, .60 and .79, .56 and .77 , and .73 and .90 . The Loyalty factor includes the characteristics of lifetime commitment, loyalty, and strong moral values. Factor loadings for the importance and satisfaction scales, respectively, were .86 and $.33, .89$ and .89 , and .59 and .77 . Shared Values (and the respective factor loadings) include belief in God (.97 and .98), religious commitment (.86 and .83), and good parenting (.21 and .33). Factor intercorrelations ranged from lows of .27 and .34 between the importance and satisfaction scale factors of Love and Loyalty, respectively, to a high of .70 between the satisfaction scale factors of Love and Shared Values. 
The WEL (Myers et al., 1998) is a 120 -item paperand-pencil instrument that assesses 17 dimensions of wellness depicted in the Wheel of Wellness model (see Myers, Sweeney, \& Witmer, 2000). These dimensions represent characteristics of healthy persons that were identified through cross-disciplinary research. The model is based in Adlerian counseling theory and identifies five major life tasks that are necessary for achieving wellness: work and leisure, friendship, love, spirituality, and self-direction. The life task of self-direction includes the 12 subtasks of sense of worth, sense of control, emotional awareness and management, realistic beliefs, problem solving and creativity, sense of humor, nutrition, exercise, stress management, self-care, gender identity, and cultural identity.

Each item in the WEL is a statement to which respondents reply using a 5-point Likert-type scale that ranges from strongly disagree (1) to strongly agree (5). Scores are the sum of item scores for each of the items in the subscales. Two-week test-retest reliabilities for the WEL subscales ranged from .72 (sense of worth) to .94 (self-care) for all subscales except cultural identity, for which the reliability coefficient was .68 . Alpha coefficients for all but two subscales ranged between .72 and .89 . The alpha for leisure was .61, and for nutrition the coefficient was .66 (Hattie, Myers, \& Sweeney, 2004). Concurrent validity coefficients with Testwell (National Wellness Institute, 1991) range from .35 to .77 for similar scales.

\section{Analyses}

Descriptive statistics were computed to describe the participants and for purposes of comparison with available norm groups. Existing norm groups for the CHARISMA $(N=201)$ and WEL $(N=480)$ scales were used, both including only married persons living in the United States. A series of $t$ tests were computed to determine possible differences between the groups.

\section{Results}

A total of 45 individuals living in arranged marriages in India participated in the study. The data from the participants in India were compared with existing data on married individuals in the U.S. who did not have arranged marriages. Selected demographic descriptors of the Indian and United States participants are shown in Table 1. As can be seen from this table, there were approximately equal numbers of men and women among the Indian participants, slightly more women than men in the WEL sample, and over two thirds of persons in the CHARISMA sample were women. Over half of the Indian participants (53.3\%), almost half of the persons in the U.S. WEL sample (46.3\%), and one third of the persons in the CHARISMA sample (32.8\%) were over 45 years of age. Almost $98 \%$ of the Indian participants had at least a bachelor's degree, as compared with $42 \%$ of the WEL and $41.8 \%$ of the CHARISMA norm groups.

TABLE 1

Selected Demographic Descriptors of Participants From India and the United States

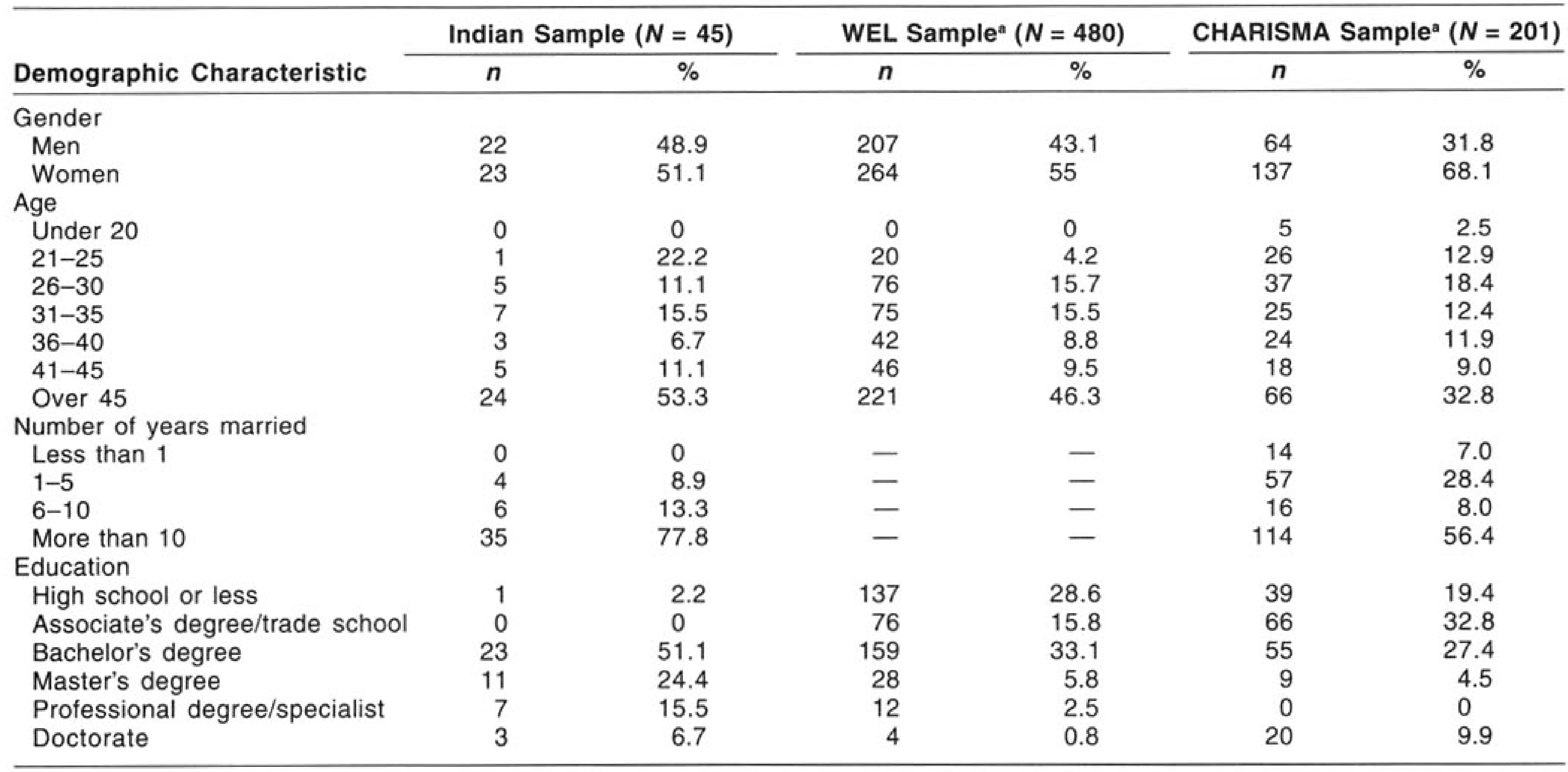

Note. WEL $=$ Wellness Evaluation of Lifestyle Inventory. CHARISMA = Characteristics of Marriage Inventory. Dash indicates data were not available.

aNorm groups including only married persons living in the United States. 
Information on length of marriage was not available for individuals in the WEL sample. Most of the participants from India $(77 \%)$ had been married more than 10 years, while over half $(56 \%)$ of the persons in the CHARISMA sample were in long-term marriages (i.e., 20 years or longer). The Indian participants who had been married for over 10 years reported having had less influence on the marriage decision-making process when compared with those who had married more recently. The majority of the Indian couples had at least one child and lived in nuclear families.

\section{Descriptive Statistics}

Descriptive statistics were computed for the CHARISMA and WEL inventories for the participants from India and compared with existing norms for the two instruments. These statistics are shown in Tables 2 and 3, along with analyses of differences between participants in the Indian and U.S. samples (CHARISMA and WEL). As shown in Table 1, scores for persons in the U.S. norm group were higher than those for the Indian participants on the CHARISMA importance subscale $(p<.05$, small effect) and two of the three importance factors: Love $(p<.01$, medium effect) and Loyalty $(p<$ .05 , medium effect). There were no differences between the Indian and U.S. participants on the CHARISMA satisfaction subscale or any of its three factors. A $t$ test of the differences in means for overall marriage satisfaction for both groups was not significant.

The results of a series of $t$ tests for the 17 subscales and two composite scales (Self-Direction and Total Wellness) of the WEL are shown in Table 3 . The participants from India scored significantly higher on spirituality $(p<.01$, small effect), nutrition ( $p<.01$, large effect), and cultural identity $(p<.01$, medium effect). Participants in the U.S. sample (WEL norm group) scored higher on realistic beliefs and work $(p<.01$, large effect), sense of humor ( $p<.01$, medium effect), and self-care $(p<.05$, small effect). There was no difference between the Indian participants and the persons in the WEL norm group on the Love scale of the WEL.

Unfortunately, the Indian sample was too small to study potential gender or other within-group differences that could shed further light on the nature of these findings.

\section{Discussion}

Comparisons of the CHARISMA scores for the Indian and U.S. participants revealed that there was a significant difference in importance ratings for marriage characteristics but not in satisfaction ratings. Therefore, while certain characteristics are viewed as differentially important for marriage satisfaction in the two countries examined, these same characteristics do not affect satisfaction with one's current marriage relationship. Although the overall effect for the factor assessing importance of marriage characteristics was small, examination of the factors underlying importance suggest some essential differences between the two groups.

No difference was found for the factor of Shared Values as important for marriage satisfaction, but differences were found for both the Love and Loyalty factors. In both instances, the effect sizes were medium, and the means for the persons in the U.S. sample were higher than the means for the persons in the Indian sample. These results suggest that differences between the two groups do, in fact, exist. In the United States, where marriages of choice predominate, individuals place a high priority on love as a precursor to marriage and marriage satisfaction and also on loyalty as an important characteristic of satisfaction with marriage. In India, where marriage partners are chosen by the families of the partners rather than by the individuals themselves, love is a less important precursor to marital happiness. Similarly, loyalty is viewed differently by each group in terms of its impor-

\section{TABLE 2}

\section{Descriptive Statistics and $t$ Tests for CHARISMA Scales for Participants From India and the United States}

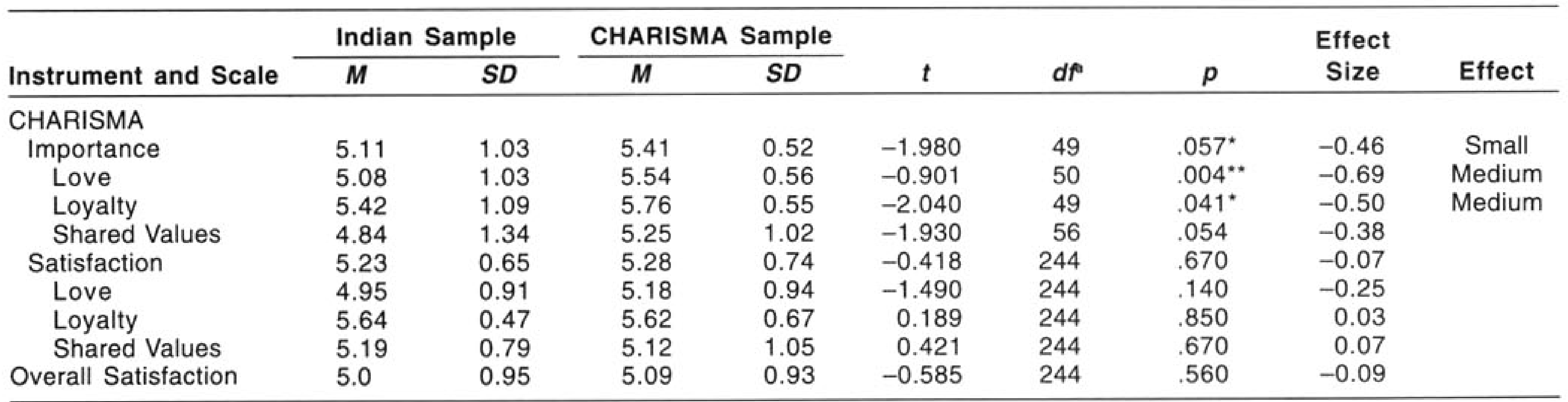

Note. $\mathrm{WEL}=$ Wellness Evaluation of Lifestyle Inventory. CHARISMA = Characteristics of Marriage Inventory

aWhere violations of homogeneity of variance occurred, the degrees of freedom were adjusted.

${ }^{*} p<.05 .{ }^{* *} p<.01$. 
TABLE 3

Descriptive Statistics and $t$ Tests for WEL Scales for Participants From India and the United States

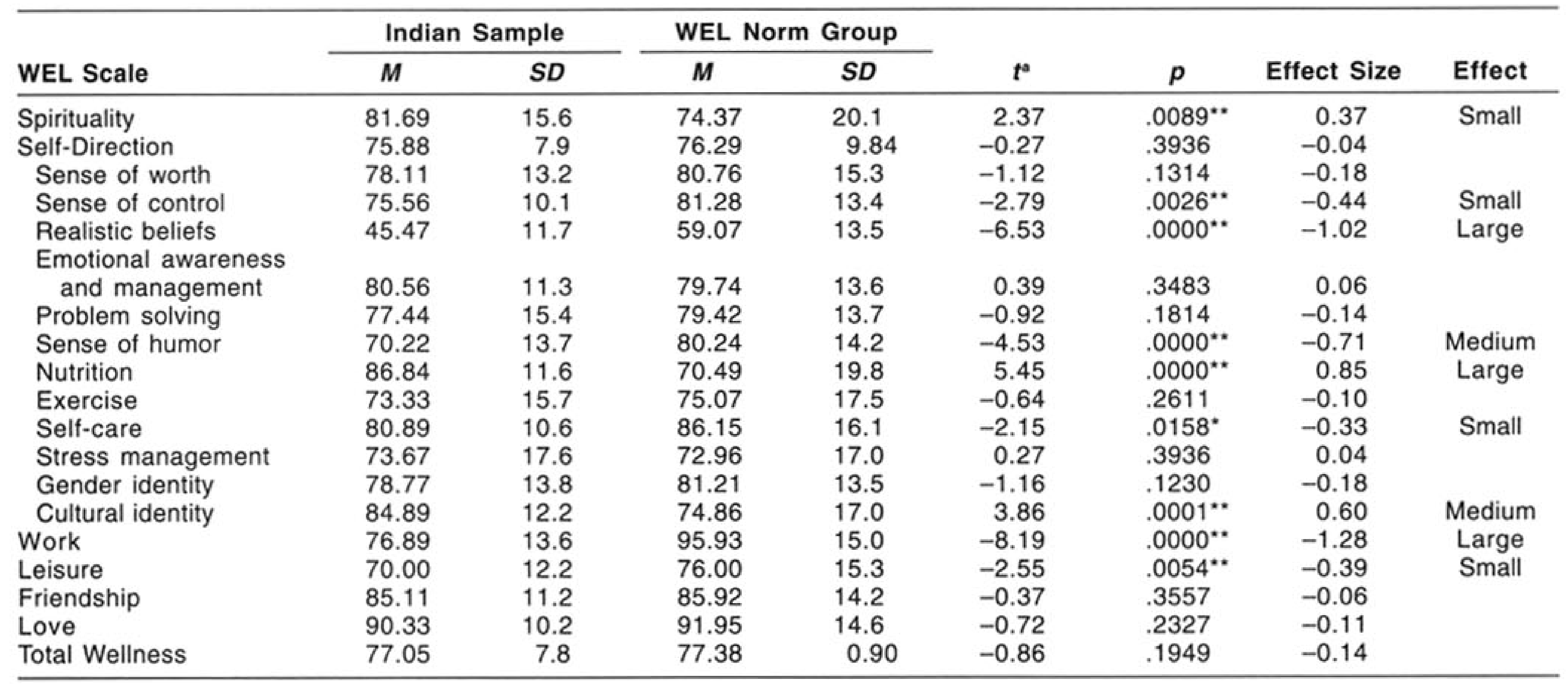

Note. $\mathrm{WEL}=$ Wellness Evaluation of Lifestyle Inventory.

ad $=514$.

" $p<.05 . " * p<.01$.

tance to a marriage, yet this factor does not discriminate between the two groups when marriage satisfaction is considered.

Overall, there was no difference in marriage satisfaction between the participants in India living in arranged marriages and those in the United States living in marriages of choice, suggesting that regardless of factors considered important to marriage, satisfaction in one's marriage relationship is not affected. This finding was particularly pleasing to one coauthor, a citizen of India who has been living in an arranged marriage for 7 years. As a student in a counselor education training program wherein her peers share a preference for feminist theory and philosophy, the possibility of satisfaction in an arranged marriage has often been greeted with curiosity, questions, and disbelief. Thus, the present findings suggest that contrary to Western beliefs, it is possible that men and women in arranged marriages can be happy and satisfied. The finding of no difference in love wellness among the groups was also of interest as well as aids in the interpretation of the previous results. The findings concerning the greater importance of love and loyalty factors in U.S. marriages could be influenced by the fact that in this country individuals actively select mates, and therefore, more thought is given to the desired characteristics of a potential mate. In arranged marriages, individuals marry according to their family's wishes, and the focus is on accepting and adjusting to partners after marriage. Thus, love is viewed in a different manner by persons in India and is not seen as a necessary precursor to marriage. Instead, love is expected to grow as the spouses learn more about each other as the years go by. Given the lack of significant differ- ences in love wellness indicated in this study, this finding suggests that cultural values relative to love and marriage mitigate for satisfaction regardless of the precursors to the marriage (i.e., personal choice or family arrangement).

Comparisons of the WEL results indicated several differences that perhaps can be explained based on understandings of cultural variations between the two countries. The participants from India indicated higher scores on the nutrition subscale of the WEL (large effect size), which could be influenced by the fact that persons in this sample consisted of middle-class Indian families who could afford a more nutritious and balanced diet. The items on the WEL subscale reflect nutrition choices for balanced meals with adequate vegetables, fruits, and whole grains, staples of the Indian diet, as well as regular meals daily. Fast foods, frequently consumed by Americans, are less available in Indian cities and virtually nonexistent in small towns outside of major population centers.

The score on the cultural identity subscale of the WEL was higher for the Indian participants (medium effect size), possibly reflecting the greater influence of caste and cultural backgrounds in India than is found in the United States population. Furthermore, collectivism fostered by the Indian culture might contribute to a greater sense of pride in one's cultural heritage, identification with one's cultural background, greater cohesiveness within groups, and a feeling of greater support from those who share one's cultural values, all of which are reflected in items on the WEL cultural identity subscale. 
Similarly, wellness scores on the spirituality subscale of the WEL were higher for the Indian participants, who live in a culture that is predominantly Hindu as compared with the culture of the United States where a large variety of spiritual practices exist. Although the effect size of this difference was small, it suggests a need for further exploration of spiritual wellness in societies where spiritual beliefs and practices differ from those found in Western nations. In factor analytic studies of the WEL (Hattie et al., 2004), the cultural identity and spirituality subscales load on the same factor. Future studies of the factor structure of the WEL with crosscultural samples are needed to determine if the factors underlying wellness are uniform across cultures (as found with the current participants) or whether they vary and the types of variations that may occur.

The large effects for differences in work and realistic beliefs were of interest. The items in the WEL work subscale predominantly reflect satisfaction with one's work. The current findings suggest that the United States participants are significantly more satisfied with their work than are persons in India. The reasons for higher wellness, as measured by the WEL work subscale items, include such things as feeling appreciated in one's work, feeling that one's skills and abilities are appropriately used, having control over the conditions affecting one's work, and looking forward in a positive sense to the work one does each day. Perhaps these circumstances are less prevalent in Indian culture, where unemployment is much higher and jobs of choice are less available. It could be that the highly educated Indian participants were unable to obtain employment in their home area in positions commensurate with their level of education and skills. Indian workplaces follow a fairly rigid structure and hierarchy, with rewards based on experience rather than merit. Many individuals stay in the same place of employment throughout their career. Also, Indian society values a few conventional professions, such as engineering and medicine, to the exclusion of others. Alternately, differences in cultural values and beliefs could result in factors other than those measured in the WEL that are responsible for work satisfaction.

The WEL realistic beliefs subscale is based in Ellis's (1973) explanation of irrational beliefs. In fact, the items in the WEL realistic beliefs subscale are direct statements of five of the more common irrational beliefs, including "I must be liked or loved by everyone to feel worthwhile," "I am often disappointed because my expectations are not met," and "I am responsible for keeping other people happy." Higher scores reflect more rational beliefs. Further exploration of cultural beliefs and values is needed to determine factors underlying the differing responses of the two groups included in this study. In particular, replication with larger numbers of persons in India could provide sufficient data for comparisons of the individual items in the realistic beliefs subscale to determine specifically where differences exist between the two cultures. Such comparisons were not possible in this study because scores for the individual items for all of the WEL subscales were not available.

The lower scores on the humor subscale for the Indian participants were interesting, particularly given the strength of the effect. Ferro and Gabriella (1986) compared verbal humor in India and in Western cultures in an attempt to determine whether humor was dependent on language and suggested that there are no cross-cultural differences in humor between the two sets of cultures. In a much earlier study, Sinha and Misra (1960) found that sense of humor was actually a valued characteristic for engineers in India, as was seriousness. More recently, Davidson and Harrington (2002) revealed that humor is a valued characteristic in Buddhist cultures. Although Indians primarily practice Hinduism, Buddhism also developed in India and reflects aspects of Indian cultural values. The items of the WEL that constitute the humor subscale were designed to assess the ability to laugh at oneself, to value the use of humor in dealing with the circumstances of life, and to measure the frequency of one's laughter. It would be interesting to examine the responses to each of these items in samples of married couples or individuals from the United States who were matched on selected demographic characteristics, such as age, gender, and education. Such research could help to determine the reasons underlying the differing responses obtained in the current study for the Humor scale. Unfortunately, the nature of the sample and the use of preexisting norm group scores precludes further analysis of the findings in the current study.

Similarly, higher standards of living permit and encourage higher degrees of leisure, which could explain the higher scores on the WEL leisure scale of the U.S. participants compared with those of individuals in India. In India, which is less affluent than the United States is, individuals historically have had less time for leisure activities as a consequence of the need to work to meet and sustain basic needs (Brinkerhoff, Fredell, \& Frideres, 1997; Verma, 1999). At the same time, leisure has been found to correlate positively with life satisfaction for employees in India (Singh \& Joseph, 1996), and, in a study of mid-life Indian adults, Tikoo (1996) found no gender differences in the perceived importance of leisure. The items on the leisure scale of the WEL assess the extent to which one values leisure activities, experiences satisfaction with one's leisure activities, and makes time for leisure activities. The differences that were found in the present study may represent an artifact of the methods used, particularly the use of an existing norm group for the WEL that differs in significant ways from the Indian participants. Further research with larger and matched samples of participants could reveal the true nature of cross-cultural differences (or lack of differences) in leisure wellness.

The higher sense of control for the U.S. sample as measured by scores on the WEL sense of control subscale (small effect) could result from the Western emphasis on individu- 
alism as opposed to the collectivistic focus in India. An additional factor influencing this could be the Indian belief in "fate," which is the concept that life events are predetermined; thus, individuals do not have control over them. Furthermore, a low sense of control in the Western sense, or having an external locus of control, may not only be more prevalent but also more admired in Eastern cultures (Matthew, 1985). Differences in spiritual as well as cultural values and beliefs could contribute to the current results. Again, further studies of the items underlying this scale could provide additional information to aid in interpretation of these results.

The demographic variables included in this study suggest that there were some important differences between the Indian and U.S. samples that may have biased the results in unknown ways. There were more participants overall in the U.S. norm groups, and most of them were women. Women in Western cultures tend to be more individualistic in their approach to life and marriage; thus, a potential source of bias could have been introduced relative to the importance of, or satisfaction with, various characteristics of marriage. Most of the participants in both the Indian and the U.S. groups were older and married for a long time, suggesting greater marital satisfaction than might be present in persons married for shorter periods of time. It would be important to control for length of marriage in future studies of marital satisfaction across cultures if the present results are to be confirmed.

The differences in educational level could also have biased the results in that the Indian participants were more highly educated than the U.S. participants. Kurdek (1991) reported that couples with lower levels of education were most likely to separate during the first years of marriage. Support for a relationship between educational level and marital satisfaction also was reported by Larson and Holman (1994). Thus, it is possible that educational level was a confound in the research design and masked true cross-cultural differences in marital satisfaction. We recommend that level of education be controlled in future cross-cultural studies to verify or refute the present findings. Replication of the current study with larger and more representative samples, particularly with persons from India having less than a bachelor's degree, is needed to further examine the findings of the present study.

Certainly the small sample size of the Indian participants is a factor requiring the results to be interpreted with caution. Furthermore, as mentioned earlier, it is possible that the underlying nature of wellness and wellness components (e.g., irrational beliefs) may differ for Indian women. At the same time, the lack of empirical studies in this area combined with the current findings imply a need for additional cross-cultural research to examine the relationships among love and wellness in various cultural groups. This would include additional groups of individuals in India as well as those from other countries and cultures.
The findings of this study have implications for counselors and counselor educators working with individuals from India. The results reveal the need for all of us, as professional counselors, to become more aware of our own biases and preconceived notions. It is extremely important for counselors to be aware of possible differences while working with individuals, couples, and families from different cultures, in this case India, in order to develop and implement appropriate interventions.

\section{Conclusion}

The purpose of this study was to examine possible differences in marital satisfaction and wellness between persons living in India in arranged marriages and persons living in the United States in marriages of choice. The results provide no support for differences in marital satisfaction or love aspects of wellness in relation to arranged marriages. Although this is not a case in favor of arranged marriages, it provides no support for a position opposing this tradition. Replication of this study with larger samples may reveal withingroup differences, particularly gender differences, that were masked in the present study. Further research on the relationships between cultural differences, cultural values, and characteristics of marriages are needed to explain these relationships and provide a knowledge base for cross-cultural couples counseling. Finally, because of the nature and number of analyses conducted in this study, it is possible that Type I errors could have occurred. Replication could also be conducted to either confirm or refute the statistically significant findings revealed in this study.

\section{References}

Brinkerhoff, M. B., Fredell, K. A., \& Frideres, J. S. (1997). Basic minimum needs, quality of life and selected correlates: Explorations in villages in Northern India. Social Indicators Research, 42 , 245-281.

Brubaker, T. H., \& Kimberly, J. A. (1993). Challenges to the American family. In T. H. Brubaker (Ed.), Family relations: Challenges for the future (pp. 3-16). Newbury Park, NJ: Sage.

Buss, D. M., Abbott, M., Angleitner, A., Biaggio, A., BlancoVillasenor, A., Bruchon-Schweitzer, M., et al. (1990). International preferences in selecting mates: A study of 37 cultures. Journal of Cross-Cultural Psychology, 21, 5-47.

Chang, C. Y., \& Myers, J. E. (1997). Understanding and counseling Korean Americans: Implications for training. Counselor Education and Supervision, 37, 35-49.

Davidson, R. J., \& Harrington, A. (Eds.). (2002). Visions of compassion: Western scientists and Tibetan Buddhists examine human nature. London: Oxford University Press.

Dion, K. K., \& Dion, K. L. (1993). Individualistic and collectivistic perspectives on gender and the cultural context of love and intimacy. Journal of Social Issues, 49(3), 53-69. 
Ellis, A. (1973). Humanistic psychotherapy: The rational emotive approach. New York: Julian.

Ferro, L., \& Gabriella, E. (1986). Language, thought, and Tamil verbal humor. Current Anthropology, 27, 265-272.

Gottman, J. M. (1994). What predicts divorce? The relationship between marital processes and marital outcomes. Hillsdale, NJ: Erlbaum.

Hattie, J. A., Myers, J. E., \& Sweeney, T. J. (2004). A factor structure of wellness: Theory, assessment, analysis, and practice. Journal of Counseling \& Development, 82, 354-364.

Heyman, R. E., Sayers, S. L., \& Bellack, A. S. (1994). Global marital satisfaction versus marital adjustment: An empirical comparison of three measures. Journal of Family Values, 8, 432-446.

Kail, R. V., \& Cavanaugh, J. C. (2000). Human development: A lifespan view. Belmont, CA: Wadsworth.

Kurdek, L. A. (1991). Marital stability and changes in marital quality in newly wed couples: A test of the contextual model. Journal of Social and Personal Relationships, 8, 27-48.

Larson, J. H., \& Holman, T. B. (1994). Predictors of marital quality and stability. Family Relations, 43, 228-237.

Larson, J. H., Holman, T. B., Klein, D. M., Busby, D. M., Stahmann, R. F., \& Peterson, D. (1995). A review of comprehensive questionnaires used in premarital education and counseling. Family Relations, 44, 245-248.

Matthew, G. (1985). Locus of control: A conceptual analysis. Indian Psychological Review, 28, 15-18.

Murstein, B. I. (1987). A clarification and extension of the SVR theory of dyadic pairing. Journal of Marriage and the Family, 49, 929-933.

Myers, J. E., Sweeney, T. J., Hattie, J. A., \& Witmer, J. M. (1998). The Wellness Evaluation of Lifestyle. Palo Alto, CA: MindGarden.

Myers, J. E., Sweeney, T. J., \& Witmer, J. M. (2000). The Wheel of Wellness, counseling for wellness: A holistic model for treatment planning. Journal of Counseling \& Development, 78, 251-266.

National Wellness Institute. (1991). Testwell. Stevens Point, WI: Author.

Olson, D. H., Fournier, D. G., \& Druckman, J. M. (1987). PREPARE/ENRICH counselor's manual. Minneapolis, MN: PREPARE/ENRICH.

Orbuch, T. L., \& Custer, L. (1995). The social context of married women's work and its impact on Black husbands and White husbands. Journal of Marriage and the Family, 57, 333-345.
Rosen-Grandon, J., Hattie, J. A., \& Myers, J. E. (2002). Assessing successful committed relationships: CHARISMA, The Characteristics of Marriage Inventory. Unpublished manuscript.

Rosen-Grandon, J., Myers, J. E., \& Hattie, J. A. (2004). The relationship between marital characteristics, marital interaction processes, and marital satisfaction. Journal of Counseling \& Development, 82, 58-68.

Shachar, R. (1991). His and her marital satisfaction: The double standard. Sex Roles, 25, 451-467.

Sher, T. G. (1996). Courtship and marriage: Choosing a primary relationship. In N. Vanzetti \& S. Duck (Eds.), A lifetime of relationships (pp. 243-264). Pacific Grove, CA: Brooks/Cole.

Singh, P., \& Joseph, G. (1996). Life satisfaction in relation to leisure and socio-cultural-sports activities. Indian Journal of Psychometry and Education, 27, 61-71.

Sinha, D., \& Misra, H. (1960). Qualities desirable for engineering students and profession: I. Teachers sample. Journal of Psychological Researches, 5, 10-21.

Spanier, G. B. (1976). Measuring dyadic adjustment: New scales for assessing quality of marriage and similar dyads. Journal of Marriage and the Family, 38, 15-28.

Sternberg, R. J. (1986). A triangular theory of love. Psychological Review, 93, 119-135.

Tikoo, M. (1996). An exploratory study of differences in developmental concerns of middle-aged men and women in India. Psychological Reports, 78(3, Pt. 1), 883-887.

Udry, R. J. (1974). The social context of marriage (3rd ed.). Philadelphia: Lippincott.

Verma, S. (1999). Socialization for survival: Developmental issues among working street children in India. In M. Raffaelli \& R. W. Larson (Series Eds.), Homeless and working youth around the world: Exploring developmental issues. New Directions for Child and Adolescent Development, No. 85 (pp. 5-18). San Francisco: Jossey-Bass.

White, L. (1994). Growing up with single parent and stepparents: Long-term effects on family solidarity. Journal of Marriage and the Family, 56, 935-948.

Xiaohe, X., \& Whyte, K. J. (1990). Love matches and arranged marriages: A Chinese replication. Journal of Marriage and the Family, 52, 709-722

Yelsma, P., \& Athappilly, K. (1988). Marriage satisfaction and communication practices: Comparisons among Indian and American couples. Journal of Comparative Family Studies, 19, 37-54. 